\title{
Cellulolytic Cocci Occurring in the Rumen of Sheep Conditioned to Lucerne Hay
}

\author{
BY A. KISTNER* AND L. GOUWS \\ National Chemical Research Laboratory, South African Council for \\ Scientific and Industrial Research, Pretoria, South Africa
}

(Received 23 August 1963)

\section{SUMMARY}

A method is described for the isolation in pure culture of the predominant cellulolytic bacteria which occur in the ovine rumen. Ten isolates of cocci were obtained from the rumen contents of one sheep conditioned to lucerne hay, and were identified as Ruminococcus albus. All ten isolates degraded xylan in addition to cellulose and cellobiose and a comparative study of the end-products of fermentation of xylan and cellobiose was made. The rates of growth on cellulose and cellobiose were compared, and the role of these cocci in the breakdown of the fibrous part of the diet assessed.

\section{INTRODUCTION}

A complete ecological analysis of the rumen population, including information on identity, metabolic functions and nutrition of the individual microbial species is necessary for a more complete understanding of the metabolism of ruminants (Bryant, 1963). Although considerable advances have been made in recent years in knowledge of the most important species of bacteria in the rumen of cattle and sheep (Bryant, 1959; Hungate, 1960, 1963), little work has been directed specifically to study the relationships between the diet of the animal, the predominant types of bacteria in the rumen, and the end-products of fermentation which they make available to their host. A study of this nature with particular reference to typical diets consumed by sheep in South Africa has been undertaken in this laboratory (Gilchrist \& Kistner, 1962). It has been shown (Kistner, Gouws \& Gilchrist, 1962) that the predominant cellulolytic bacteria in the rumen of sheep fed lucerne hay are cocci which produce rhizoid colonies; these cocci rapidly decrease in number when the animals are changed to a ration of poor quality teff hay and are eventually replaced by rods as the major cellulolytic species (Kistner \& Gouws, 1962).

As part of a programme of research to discover the reasons for these changes in the ecology of the rumen, several isolates of cocci from sheep fed lucerne hay were obtained and examined. This aspect of the work is reported in the present paper. Their relationship to the cellulolytic cocci isolated from the rumen of cattle by Bryant, Small, Bouma \& Robinson (1958) is discussed. It was found that the organisms degraded xylan, in addition to cellulose and cellobiose, and a comparative study of the end-products of xylan and cellobiose metabolism was made. The role

\footnotetext{
* Postal address : c/o The Chief, Veterinary Research Institute, P.O. Onderstepoort, Transvaal, South Africa.
} 
of these organisms in the breakdown of the fibrous part of the diet and their contribution to the fermentation products found in the rumen was also assessed.

\section{METHODS}

Cultures. The cultures studied included ten isolates of cellulolytic cocci obtained on three dates from counts in the $1 / 10^{6}$ dilutions in cellulose agar of rumen fluid from one sheep, K11, which had been conditioned for at least 4 months to lucerne hay, similar in composition to that used by Kistner et al. (1962). Strains FD 1, c 94, 7 and 20 were obtained through the courtesy of Dr M. P. Bryant.

Media for isolations. Cellulose agar medium (Kistner, 1960) from which Antifoam $B$ was omitted, and a similar medium in which cellobiose $(0.5 \%, \mathrm{w} / \mathrm{v})$ and cysteine. $\mathrm{HCl}(0 \cdot 05 \%, \mathrm{w} / \mathrm{v})$, replaced the cellulose and sodium dithionite, were used.

Phosphate buffer. Sterile phosphate buffer $0 \cdot 066 \mathrm{M} \mathrm{(pH} \mathrm{6.8)} \mathrm{containing} \mathrm{cysteine.} \mathrm{HCl}$ $(0.05 \%, \mathrm{w} / \mathrm{v})$ and indigodisulphonate $(0.0005 \%$, w/v) was used for breaking up the colonies.

Fermentation tests. The basal medium for fermentation tests was similar to the basal medium of Kistner (1960) except for the omission of agar and Antifoam B, the replacement of sodium dithionite by cysteine. $\mathrm{HCl}(0.05 \%, \mathrm{w} / \mathrm{v})$, and the use of Seitz-filtered rumen fluid to give a clear medium. Thermostable substrates (e.g. cellulose, starch, esculin, sodium lactate) were added to the basal medium in final concentrations of $0.5 \%(\mathrm{w} / \mathrm{v})$, after which the medium was distributed in $5 \mathrm{ml}$. amounts in rubber-stoppered, screw-cap, $1 \mathrm{oz}$. bottles and autoclaved $\left(121^{\circ}\right.$ for $25 \mathrm{~min}$.). Stock solutions of thermolabile carbohydrates were sterilized separately by Seitz-filtration, added to the autoclaved basal medium in final concentrations of $0.5 \%(\mathrm{w} / \mathrm{v})$, and distributed with aseptic and anaerobic precautions.

Acetylmethylcarbinol formation. Basal medium containing cellobiose $(0.5 \%, \mathrm{w} / \mathrm{v})$ was used for the Voges-Proskauer test.

Gelatin liquefaction. Basal medium + cellobiose $(0 \cdot 05 \%, w / v)+$ gelatin $(0 \cdot 4 \%$, $\mathrm{w} / \mathrm{v}$ ) was used to test for proteolytic activity.

Determination of end-products of metabolism. Medium containing cellobiose (B.D.H., $0.5 \%$, w/v), or xylan (Nutritional Biochemicals Corporation, 0.5\%, w/v) in basal medium similar to that used for the fermentation tests was used. The complete medium was prepared in $50 \mathrm{ml}$. quantities in rubber-stoppered, screw-cap, $6 \mathrm{oz}$. bottles purged with $\mathrm{O}_{2}$-free $\mathrm{CO}_{2}$ and sterilized by autoclaving $\left(121^{\circ}\right.$, $25 \mathrm{~min}$.).

Growth rate tests. The medium consisted of basal medium similar to that used for the fermentation tests with added cellobiose $(0.5 \%, \mathrm{w} / \mathrm{v})$ or cellulose $(1 \cdot 2 \%, \mathrm{w} / \mathrm{v})$. The complete medium was prepared in $50 \mathrm{ml}$. quantities in $6 \mathrm{oz}$. bottles.

\section{Isolations}

Picking colonies. Colonies were picked by using a $2 \mathrm{ml}$. automatic syringe provided with a 15-gauge stainless steel needle, the bevel of which had been ground away and the front $0 \cdot 25$ in. bent to form a $90^{\circ}$ elbow. The stopper of the roll bottle containing the colonies was removed under pressure of sterile $\mathrm{O}_{2}$-free $\mathrm{CO}_{2}$ (Kistner, 1960), and the bottle was thus continuously purged throughout the whole operation to protect the colonies against exposure to oxygen. The syringe and needle were 
filled with buffer, and the flat end of the needle was located over a selected colony with the help of a slanted beam of light from a microscope lamp. The needle was driven through the agar until it made contact with the glass wall of the bottle over its entire circumference. By allowing the spring-loaded plunger of the automatic syringe to jump back through about $0 \cdot 25$ in., the colony was sucked into the front part of the needle. From here it was washed into the barrel of the syringe by drawing up about $1.5 \mathrm{ml}$. of buffer. After expelling any gas bubbles trapped in the syringe, the bent needle was replaced by a similar sterile straight one, and the air displaced from this needle by inverting the syringe and spilling a few drops of buffer. The plunger was then brought to the $1 \mathrm{ml}$. mark.

Dispersion. To break up the colony thus sucked into the syringe into single organisms as far as possible, the blunt needle of the syringe was forced through the vaccine cap of a second roll bottle until it came to rest firmly against the bottom. By depressing the plunger, the colony was forced out between the flat end of the needle and the smooth bottom of the bottle, thus shearing it apart. The buffer was then sucked back into the syringe and the process repeated until all the lumps of agar had been broken up and dispersed. The resulting suspension was drawn into the syringe and the needle withdrawn from the bottle.

Distribution. The blunt needle on the syringe was next replaced by a regular 20-gauge $\mathbf{1 \cdot 2 5} \mathrm{in}$. hypodermic needle, and the air displaced from this by spilling a few drops of the suspension. The rest of the suspension was injected through the rubber stopper into a $1 \mathrm{oz}$. dilution bottle containing $9 \mathrm{ml}$. molten cellulose agar medium, and the contents of the bottle mixed by alternately filling and emptying the syringe ten times. One millilitre of this first dilution was withdrawn with the same automatic syringe and injected into the next dilution bottle. With the same automatic syringe this process was repeated until four tenfold dilutions of the original suspension had been prepared. Four roll bottle cultures (Kistner, 1960) were prepared from each dilution and incubated at $38^{\circ}$ until growth was observed.

Transfers. The transfers on cellulose agar were repeated until the cultures looked pure on inspection of the colony forms and on microscopic examination of smears from at least three colonies stained by Gram's method. The cultures were then put through at least two successive transfers on cellobiose agar media to show up colonies of any contaminants which might have been overlooked on the opaque cellulose medium. When no contaminants were detected after microscopic examination of about one-third of the colonies in a roll bottle of the fourth dilution, the culture was regarded as pure, and it was transferred back to cellulose agar medium.

Maintenance. Stock cultures were maintained on cellobiose slopes and kept in a box with solid $\mathrm{CO}_{2}$. They were subcultured every 6-8 months.

Inoculum. The stock culture from the solid $\mathrm{CO}_{2}$ box was inoculated to a cellobiose slope and incubated for $18 \mathrm{hr}$ at $38^{\circ}$. The resulting growth was suspended in $2 \mathrm{ml}$. buffer, with anaerobic precautions, and $0.1 \mathrm{ml}$. portions of the suspension used for all inoculations except for the growth rate tests, for which a denser suspension from a $24 \mathrm{hr}$ culture was used.

\section{Physiological tests}

Fermentation tests. The fermentation tests listed in Table 1 were carried out at $38^{\circ}$ and read after 1, 2, 3 and sometimes 7 days of incubation.

Growth rate tests. The liquid media mentioned above were warmed to $38^{\circ}$, 
inoculated, and, after thorough mixing, samples $(1 \mathrm{ml}$.) of culture were withdrawn for zero-time counts in cellobiose agar (Kistner, 1960). Further counts were made after incubation for 18, 24 and $48 \mathrm{hr}$.

\section{End-products of metabolism}

The end-products of cellobiose or xylan fermentation by the strains of cocci listed in Table 3 were determined after incubating for $48 \mathrm{hr}$ at $38^{\circ}$.

Gas. The gas produced was extracted quantitatively by a Toepler pump and transferred to the chamber of a Van Slyke manometric apparatus. Carbon dioxide was removed by absorption and residual $\mathrm{H}_{2}$ and $\mathrm{CH}_{4}$ were determined by combustion (Peters \& Van Slyke, 1932).

Total organic acids. The method of Neish (1952) was used to clarify the culture liquid and to determine total organic acids.

Lactic acid. The method of Elsden \& Gibson (1954) was used.

Succinic acid was estimated according to Bril (1954).

Ethanol. Neutral volatile compounds were determined according to Neish (1952). These consisted almost entirely of ethanol as found by analysing samples of the distillate by an alcohol-dehydrogenase method based on that of Bücher \& Redetzki (1951).

Volatile fatty acids. Total and individual volatile fatty acids were determined by the gas-liquid chromatographic method of James \& Martin (1952).

\section{RESULTS \\ Characteristics of the isolates}

The main characteristics of our strains are shown in Table 1.

Colony form. In the thin films of cellulose agar in the roll bottle cultures, all ten of our isolates produced typical rhizoid colonies surrounded by circular zones of cellulolysis which increased in size with the age of the culture. The more colonies there were in a culture, the smaller they remained. Whether this was due to competition for a nutrient present in limiting concentrations or to inhibition by fermentation end-products is uncertain. Surface colonies on cellobiose agar were white, circular and convex; deep colonies in this medium were spindle-shaped.

Morphology and Gram reaction. The cocci occurred mostly in pairs, with a few single ones. Chain formation was never observed. The mean diameter of the cocci from $24 \mathrm{hr}$ cultures on cellobiose liquid medium was $1 \cdot 0-1 \cdot 1 \mu$. Capsule formation was frequently observed on cellulose agar and on cellobiose agar. Spores were never found. The Gram reaction of all our isolates was variable, even in 18 -hr cultures. With the exception of isolates $19.08 .6 \mathrm{c}$ and 19.08.6 $\mathrm{G}$, the proportion of Grampositive to Gram-negative cocci in thin smears was usually very low.

Fermentation tests. All ten of our isolates consistently showed growth on cellulose, cellobiose or xylan within $48 \mathrm{hr}$ of incubation. Three isolates fermented no other carbohydrates; the remaining seven isolates fermented D-mannose, though this was not always evident within $48 \mathrm{hr}$ of incubation. Three of the latter isolates also fermented glucose, but with two isolates growth was then obviously slower than on cellobiose medium. Isolate 22.08.6 a showed slow growth on fructose. On cellobiose medium the final $\mathrm{pH}$ value was between 5.9 and $6 \cdot 2$, appreciably higher than the 


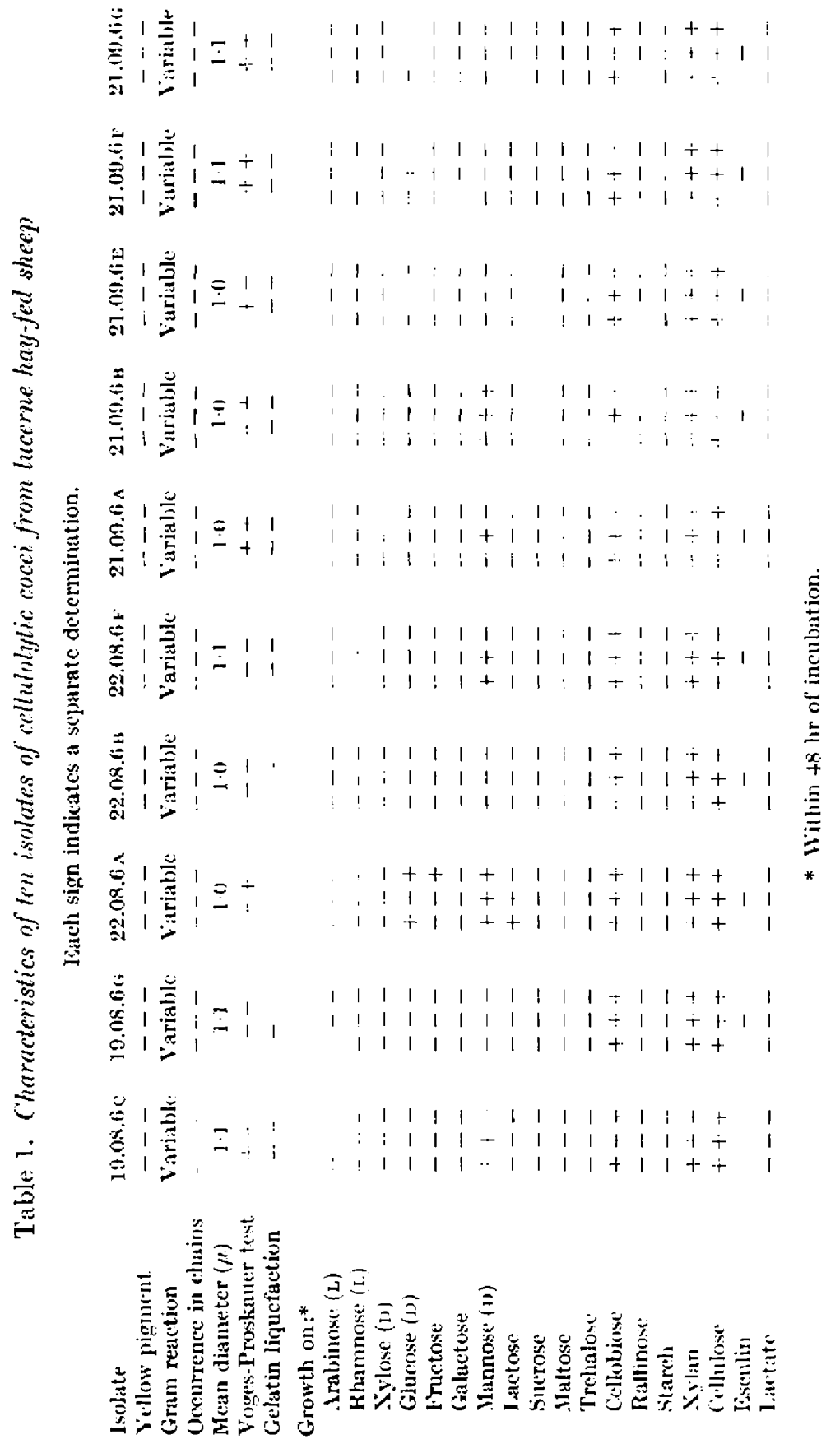


values reported by Bryant et al. (1958) for their cultures of cellulolytic cocci, probably because the medium used by these authors was less heavily buffered with bicarbonate than was ours. None of the ten isolates fermented arabinose, rhamnose, xylose, galactose, lactose, sucrose, maltose, trehalose, raffinose, starch, esculin or lactate. Gelatin liquefaction was not observed even after extended incubation periods, nor was any yellow pigment produced in any of the media used. Six of the isolates gave a positive Voges-Proskauer reaction, while one, isolate 21.09.6 E, was variable in its reaction.

Rate of growth on cellulose and cellobiose. The rapid growth of isolate $19.08 .6 \mathrm{G}$ (Table 2) in liquid media containing cellulose or cellobiose was followed by a steep decline in the number of viable organisms. The form of the growth curve on cellobiose medium shows much resemblance to the curves obtained by Bryant \& Robinson (1961) by plotting optical densities of Ruminococcus cultures against incubation time. The decrease in optical density found by these authors immediately after the growth maximum had been reached (whether due to lysis of organisms or to other causes) would coincide with the progressive decline of viability in the present experiment.

Table 2. Growth rate of cellulolytic coccal isolate 19.08.6 G on liquid media containing cellulose or cellobiose

$\begin{array}{ccc}\text { Incubation time } & \begin{array}{c}\text { Cellulose liquid } \\ \text { medium } \\ \text { (hr) }\end{array} & \begin{array}{c}\text { Cellobiose liquid } \\ \text { medium } \\ \text { (Organism/ml.) }\end{array} \\ 0 & 4.5 \times 10^{4} & 24 \times 10^{4} \\ 18 & 7 \times 10^{7} & 3 \times 10^{8} \\ 24 & 1.5 \times 10^{8} & 11.5 \times 10^{7} \\ 48 & 2 \times 10^{6} & 1.5 \times 10^{6}\end{array}$

Degradation of cellulose. The first sign of activity of the cultures on cellulose liquid medium was a viscidity of the cellulose, similar to that observed by Skinner (1960) in cultures of a cellulolytic soil organism. This was first observed after incubation for about $18 \mathrm{hr}$. At $24 \mathrm{hr}$ the disappearance of cellulose became obvious while the stickiness decreased; at $48 \mathrm{hr}$ the residual sediment occupied about one-third of the volume of the cellulose present in an uninoculated control and was of a looser and finer structure.

\section{End-products of fermentation}

The values for the amounts of end-products from cellobiose and xylan fermentations as reported in Table 3 for our own cultures are the means of determinations on at least two dates, whereas only a single estimation was run on Bryant's cultures in most cases. The concentrations of the end-products found in $48 \mathrm{hr}$ cultures on different dates were very consistent (Table $\mathbf{3}$ ).

Xylan fermentation. In the fermentation of xylan the amounts of formic, acetic and lactic acids and ethanol by isolates $19.08 .6 \mathrm{c}, 19.08 .6 \mathrm{G}, 21.09 .6 \mathrm{~A}, 21.09 .6 \mathrm{~B}$ and 21.09.6 E were very similar. These values were of the same order as those found in the corresponding cultures on cellobiose medium. In the case of Bryant's cultures FD 1, c 94, 7 and 20, the agreement between the different strains was not as good. Whereas strains 7 and 20 produced large amounts of ethanol from xylan, strains FD 1 and c 94 produced only insignificant amounts. However, the amounts of formic, 


\section{Rumen cellulolytic cocci}

acetic and lactic acids and ethanol produced by each of Bryant's strains on xylan were in fair agreement with the values obtained on cellobiose liquid medium.

Cellobiose fermentation. The fermentation of cellobiose in the liquid medium containing $\mathbf{0 . 5} \%$ of this substrate did not proceed to completion. Repeated qualitative paper chromatographic tests showed that considerable quantities of cellobiose were still present in the medium when fermentation stopped. It is not known what the limiting factor in the fermentation was, but the different strains of cocci seem to have been affected in much the same way. The recovery of carbon in the end-products was remarkably consistent for our ten isolates, ranging from $30.9 \%$ of the carbon supplied as cellobiose in the case of isolate $19.08 .6 \mathrm{c}$ to $37.0 \%$ for isolate $22.08 .6 \mathrm{~B}$.

Table 3. End-products of fermentation (mmole/100 $\mathrm{ml}.)^{*}$

In rumen fluid-cellobiose medium

\begin{tabular}{|c|c|c|c|c|c|c|c|c|c|c|}
\hline \multirow[b]{2}{*}{ Culture } & \multirow[b]{2}{*}{ Hydrogen } & \multirow[b]{2}{*}{ Ethanol } & \multicolumn{4}{|c|}{ Acids } & \multicolumn{4}{|c|}{ Acids } \\
\hline & & & Formic & Acetic & Lactic & Succinic & Ethanol & Formic & Acetic & Lactic \\
\hline $19.08 .6 \mathrm{C}$ & $0 \cdot 04$ & $0 \cdot 87$ & $1 \cdot 38$ & $1 \cdot 18$ & 0.02 & 0.0 & 0.98 & $1 \cdot 14$ & $1 \cdot 06$ & $0 \cdot 02$ \\
\hline $19.08 .6 \mathrm{G}$ & 0.85 & 1.07 & $1 \cdot 18$ & $1 \cdot 13$ & 0.06 & $0 \cdot 0$ & 0.93 & $\mathbf{1} \cdot 29$ & $1 \cdot 14$ & 0.01 \\
\hline $22.08 .6 \mathrm{~A}$ & $0 \cdot 09$ & $1 \cdot 03$ & $1 \cdot 58$ & $1 \cdot 30$ & 0.02 & $0 \cdot 0$ & - & - & - & - \\
\hline $22.08 .6 \mathrm{~B}$ & $0 \cdot 87$ & $1 \cdot 24$ & $1 \cdot 36$ & $1 \cdot 39$ & 0.02 & $0 \cdot 0$ & - & -- & 一 & 一. \\
\hline $22.08 .6 \mathrm{~F}$ & $0 \cdot 64$ & $1 \cdot 07$ & 1.33 & $1 \cdot 39$ & $0 \cdot 02$ & 0.0 & - & - & - & - \\
\hline $21.09 .6 \mathrm{~A}$ & $0 \cdot 13$ & $1 \cdot 11$ & $1 \cdot 26$ & $1 \cdot 31$ & 0.02 & $0 \cdot 0$ & $1 \cdot 14$ & $1 \cdot 21$ & $1 \cdot 10$ & 0.02 \\
\hline $21.09 .6 \mathrm{~B}$ & 0.09 & 1.05 & $1 \cdot 42$ & $1 \cdot 29$ & 0.02 & 0.0 & 0.94 & $1 \cdot 06$ & 0.91 & 0.02 \\
\hline $21.09 .6 \mathrm{E}$ & $0 \cdot 13$ & 1.00 & $1 \cdot 35$ & $1 \cdot 37$ & 0.01 & 0.0 & $1 \cdot 12$ & $1 \cdot 21$ & $1 \cdot 14$ & 0.02 \\
\hline $21.09 .6 \mathrm{~F}$ & 0.07 & 1.05 & $1 \cdot 38$ & $1 \cdot 34$ & 0.01 & $0 \cdot 0$ & - & - & 一 & - \\
\hline $21.09 .6 \mathrm{G}$ & $0 \cdot 12$ & $1 \cdot 05$ & $1 \cdot 58$ & $1 \cdot 48$ & $0 \cdot 02$ & $0 \cdot 0$ & - & - & - & - \\
\hline $\mathbf{F D}_{1}$ & $\begin{array}{c}0.05 \\
(0.0) \dagger\end{array}$ & $\begin{array}{c}0 \cdot 10 \\
(0 \cdot 0)\end{array}$ & $\begin{array}{c}1 \cdot 27 \\
(3 \cdot 12)\end{array}$ & $\begin{array}{c}1 \cdot 38 \\
(2 \cdot 38)\end{array}$ & $\begin{array}{c}0 \cdot 03 \\
(0 \cdot 14)\end{array}$ & $\begin{array}{c}0.80 \\
(1 \cdot 76)\end{array}$ & $0 \cdot 04$ & 0.53 & $0 \cdot 83$ & 0.02 \\
\hline C94 & $\begin{array}{r}0 \cdot 10 \\
(0 \cdot 0)\end{array}$ & $\begin{array}{r}0 \cdot 01 \\
(0 \cdot 0)\end{array}$ & $\begin{array}{c}0 \cdot 66 \\
(2 \cdot 72)\end{array}$ & $\begin{array}{c}0 \cdot 62 \\
(2 \cdot 32)\end{array}$ & $\begin{array}{c}0.07 \\
(0.52)\end{array}$ & $\begin{array}{c}1 \cdot 47 \\
(1 \cdot 85)\end{array}$ & $0 \cdot 04$ & 0.98 & $1 \cdot 06$ & 0.05 \\
\hline 7 & $\begin{array}{l}0 \cdot 83 \\
(0 \cdot 74)\end{array}$ & $\begin{array}{c}1 \cdot 20 \\
(3 \cdot 65)\end{array}$ & $\begin{array}{c}1 \cdot 45 \\
(3 \cdot 74)\end{array}$ & $\begin{array}{c}1 \cdot 25 \\
(3 \cdot 46)\end{array}$ & $\begin{array}{c}0 \cdot 02 \\
(0 \cdot 0)\end{array}$ & $\begin{array}{c}0 \cdot 0 \\
(0 \cdot 11)\end{array}$ & $1 \cdot 46$ & $1 \cdot 29$ & $1 \cdot 14$ & 0.02 \\
\hline 20 & $\begin{array}{c}0 \cdot 06 \\
(0 \cdot 0)\end{array}$ & $\begin{array}{c}0 \cdot 80 \\
(1 \cdot 85)\end{array}$ & $\begin{array}{c}1 \cdot 42 \\
(3 \cdot 14)\end{array}$ & $\begin{array}{c}1 \cdot 22 \\
(1 \cdot 38)\end{array}$ & $\begin{array}{c}0 \cdot 06 \\
(0 \cdot 34)\end{array}$ & $\begin{array}{c}0 \cdot 0 \\
(0 \cdot 0)\end{array}$ & 0.95 & $1 \cdot 29$ & $1 \cdot 36$ & 0.02 \\
\hline
\end{tabular}

* After subtraction of the blank values for the different metabolites, obtained by analysis of batch of medium used. The range of values for the different batches, expressed as mmole/100 ml., was-ethanol : $0.03-0.09$; formic acid : $0.40-0 \cdot 46$; acetic acid : $0.46-0.76$; lactic acid : $0.01-0.02$; succinic acid : nil.

$\dagger$ Figures in parentheses are values reported by Bryant et al. (1958) for the same cultures.

This did not include any fermentation - $\mathrm{CO}_{2}$ formed, since the bicarbonate-carbonic acid buffer system of the medium precluded determination of this end-product. The carbon recoveries which may be calculated from the data of Bryant et al. (1958) for members of their Group II vary from $31.4 \%$ for strain $B_{3} 36$ to $102 \cdot 4 \%$ for strain 7 ; in comparison, the recovery for strain 7 on our medium was only $36.5 \%$.

On the whole our ten isolates of cocci were very uniform in their production of ethanol, formic, acetic and lactic acids, but hydrogen production by isolates 19.08.6 G, 22.08.6 B and 22.08.6 F was consistently much higher than by the remaining seven isolates. None of the ten isolates produced succinic acid. The values obtained for two of Bryant's cultures, namely 7 and 20 belonging to his 
Group II, were very similar to those obtained for our isolates. However, strains FD 1 and c 94 belonging to Bryant's Group I produced large amounts of succinic acid with lesser amounts of ethanol.

The agreement between the values reported by Bryant et al. (1958) for strains FD 1, C 94, 7 and 20 and those found in the present study is not very good. Not only were the amounts of formic and acetic acids produced rather lower on our media, but the clear-cut differences between typical members of Group I and Group II with respect to hydrogen and ethanol production, found by these authors, are not nearly as apparent from the present data. On the other hand, whereas Bryant et al. (1958) regarded strain 20 as an atypical member of their Group II because no hydrogen was detected in the culture, a low production of hydrogen was found in the present study, which would bring strain 20 into line with the other members of the group.

The differences between the concentrations of the end-products of strains FD 1, c 94, 20 and 7 reported by Bryant et al. (1958) and those found in the present work may stem from differences in the composition of the media used. Both media are derived from that described by Hungate (1950) and are similar in the mineral constituents and buffer system. However, Bryant et al. (1958) added $0.5 \%$ trypticase to their medium and decreased the concentration of rumen fluid to $20 \%(\mathrm{v} / \mathrm{v})$ as compared to $30 \%(\mathrm{v} / \mathrm{v})$ in Hungate's and our media. That the latter change may influence the proportions of end-products of carbohydrate fermentation formed in the culture is shown by the work of Gill \& King (1958) who found marked shifts in the fermentation pattern of Butyrivibrio fibrosolvens when the proportions of basal medium and rumen fluid supplement were altered. Furthermore, the source of rumen fluid and the time at which it is drawn in relation to the feeding time of the animal are bound to affect the concentration of growth factors in the medium and may, therefore, influence the extent and course of carbohydrate fermentation by the cultures. It is also conceivable that the relative volumes of the culture and the gas space above it may play a part by determining the increase in the pressure of $\mathrm{CO}_{2}$ in the gas phase during fermentation and consequently determining the concentration of carbonic acid in the culture. This in turn might control the equilibrium of enzymic processes in which $\mathrm{CO}_{2}$ participates. All these factors hamper the comparison of the characteristics of new isolates with the published results of other workers, and it is possible that some of the nuances in the physiology of isolates described by different authors may have been caused by differences in the environmental conditions rather than by real differences in the enzymic constitution of the organisms. This situation will only be remedied when a medium of known composition and without rumen fluid supplement is found to support the growth of all Ruminococcus strains.

\section{DISCUSSION}

The characteristics of all our ten isolates fit the description of one species Ruminococcus albus (Hungate, 1957) as amended by Bryant et al. (1958). Although the isolates differed in Voges-Proskauer reaction, in fermentation of glucose, mannose or fructose and in the amount of hydrogen produced in the fermentation of cellobiose, these differences did not justify a division into groups.

The seven strains of this species studied in detail by Bryant et al. (1958) were all 
obtained from the rumen of cows fed lucerne hay, lucerne hay + grain or clover pasture, where they occurred in numbers of $10^{8} / \mathrm{ml}$. or more. On the other hand, Ruminococcus albus strains examined by Hungate (1957) were isolated from the fifth or sixth dilutions of rumen contents from cows fed timothy hay + concentrates, where they were often outnumbered by other cellulolytic species, especially by members of the genus Butyrivibrio. In both cases $R$. albus was not the only species of cellulolytic coccus found, $\boldsymbol{R}$. flavefaciens and intermediate types occurring either in the same animal or in animals on the same diet. Bryant et al. (1958) mentioned specifically that widely different strains of Ruminococcus were isolated from the same sample of rumen contents. In contrast, the predominant cellulolytic cocci of our sheep K 3, K 4 and K 8 (Kistner et al. 1962), and K 11 conditioned to lucerne hay, were very uniform in morphology, Gram reaction and colony shape on cellulose agar; the ten isolates examined in detail all belonged to the species $R$. albus. Yellow colonies consisting of cocci in chains were never observed in high dilutions of rumen contents of sheep on this diet; only recently have we found organisms which answer to the description of $\boldsymbol{R}$. flavefaciens, in rumen samples from sheep shortly after a change in diet from lucerne hay to poor quality teff hay. It is very difficult to ascribe the uniformity of our predominating cellulolytic cocci to any factors which differed from those operating in the experiments of the above-mentioned workers. It seems unlikely that the absence of colonies of other cellulolytic bacteria in high dilutions of rumen contents from sheep fed lucerne hay was due to selective action of the cellulose agar medium, considering that the same medium regularly supported growth of various Butyrivibrio species from sheep which were fed teff (Eragrostis tef) hay. Whether differences in the management of the animals might be responsible for the differences between the findings of different workers who have examined the cellulolytic bacteria of cattle and sheep conditioned to lucerne (or alfalfa) hay is difficult to assess, since the literature contains little reference to such details as exact composition of ration and length of the conditioning period.

From the spectrum of carbohydrates fermented by the ten coccal isolates obtained in the present work, it would appear that these organisms specialize in the fermentation of the polysaccharides associated with the fibrous portion of the diet. In fact, all ten isolates attacked xylan but did not grow on xylose, and seven isolates exhibited the peculiarity reported for aerobic and anaerobic cellulose-digesting bacteria from different habitats (McBee, 1948; Hungate, 1950; Sijpesteijn, 1951; Hall, 1952; Hulcher \& King, 1958; Ayers, 1958; Enebo, 1949) namely, preference for cellulose or cellobiose rather than glucose. The efficiency of our cocci in carrying out the function of cellulose degradation is suggested by the fact that the growth rate in vitro in a medium containing insoluble cellulose did not lag far behind that in a similar medium with cellobiose.

Of the end-products of cellobiose fermentation found in pure cultures of the ten isolates of cellulolytic cocci, only acetic acid occurs in appreciable quantities in the rumen of sheep fed lucerne hay. Formic acid and hydrogen normally do not accumulate to any extent in the rumen under most conditions 'no doubt because they are very active intermediates and are used in a range of reducing reactions as soon as they become available' (Annison \& Lewis, 1959). Beijer (1952) showed that the in vitro incubation of sodium formate with goat rumen fluid led to considerable methane formation, while McNeill \& Jacobson (1955), with bovine rumen bacteria, concluded 
that the reduction of carbon dioxide constitutes the main pathway for methane production in the rumen and that the availability of hydrogen was the chief limiting factor in this reaction. Smith \& Hungate (1958) isolated from high dilutions of rumen contents from cattle and one sheep a methanogenic organism, Methanobacterium ruminantium, which utilized hydrogen and formic acid, but no other substrates, in the formation of methane.

Ethanol has been found in the rumen of lambs (Cunningham \& Brisson, 1955) but normally does not accumulate in the rumen. Moomaw \& Hungate (1963) concluded that 'the explanation for ethanol formation in pure cultures may be that it is essential as a repository for hydrogen', whereas 'in mixed culture, such as in the rumen, the hydrogen concentration is kept low $(0.05 \%$ in the rumen) by participating in exergonic reactions forming methane, propionic acid, and butyric acid'.

Although it is known that xylans are readily and extensively metabolized in the rumen (Heald, 1953) and that similar concentrations of end-products are formed in the fermentation of cellulose and hemicellulose by mixed suspensions of rumen organisms (Gray \& Pilgrim, 1952; Bath \& Head, 1961), to our knowledge no work has been done on the end-products of xylan fermentation by pure cultures of cellulolytic rumen bacteria. Hobson \& Purdom (1961) compared the end-products of xylose and glucose fermentation by two pure cultures representative of the xylandegrading bacteria found in two sheep on a diet of hay + grass cubes. In both cultures they found qualitative and quantitative differences in the organic acids produced from these two sugars. The present work has shown that the concentrations of ethanol, and of formic, acetic and lactic acids produced in the fermentation of cellobiose and xylan by fourteen strains of cellulolytic cocci were in good agreement. This suggests that the terminal pathway of fermentation may be the same for both substrates; it is conceivable that the fermentation of xylan proceeds through a pathway which involves hexose synthesis (Wood, 1961).

Reviewing the information about the ten isolates of cellulolytic cocci we obtained from lucerne hay-fed sheep, it is clear that they are functional rumen bacteria in the sense of Elsden \& Phillipson (1948). Not only were these cocci capable of attacking cellulose and xylan, which together constitute more than one-third of lucerne hay, but they formed fermentation products which are known to occur in the rumen of sheep fed this diet or which are likely to be converted to such endproducts by other rumen bacteria. Furthermore, these cocci occurred at concentrations of about $10^{7} / \mathrm{ml}$. rumen fluid and their growth rate on cellulose in vitro under conditions aimed to resemble the rumen milieu was such that they could be expected to maintain themselves in the flowing system of the rumen. The significance of these organisms as functional cellulose digesters in the alimentary tract of herbivores is stressed by the fact that they were found to be among the more numerous cellulolytic bacteria in the rumen of several different sheep at different periods.

The authors wish to thank The Chief, Veterinary Research Institute, Onderstepoort, for facilities for carrying out this work. Appreciation is also expressed to Dr F. M. C. Gilchrist and Dr H. M. Schwartz who contributed to the manuscript through discussion and criticism. We are indebted to Dr M. P. Bryant of the Dairy Cattle Research Branch, Beltsville, Maryland, U.S.A., who supplied us with some of his previously described cultures of Ruminococcus albus and R. flavefaciens. 
This paper forms Part III of a series on 'Bacteria of the ovine rumen'; for Parts I and II see J.agric. Sci. 59, 77, 85 (1962).

\section{REFERENCES}

Annison, E. F. \& Lewis, D. (1959). Metabolism in the Rumen, p. 153. London: Methuen and Co. Ltd.

Ayers, W. A. (1958). Phosphorylation of cellobiose and glucose by Ruminococcus flavefaciens. J. Bact. 76, 515.

Bath, I. H. \& Head, M. J. (1961). The in vitro production, by rumen micro-organisms, of volatile fatty acids from cellulose and hemicellulose labelled with ${ }^{14} \mathrm{C} . J$. agric. Sci. $56,131$.

Beiser, W. H. (1952). Methane fermentation in the rumen of cattle. Nature, Lond. 170, 576.

BriL, C. (1954). Enzymic micro-determination of succinate and fumarate in tissue homogenates. Biochim. biophys. Acta, 15, 258.

Bryant, M. P. (1959). Bacterial species of the rumen. Bact. Rev. 23, 125.

Bryant, M. P. (1963). Symposium on microbial digestion in ruminants: identification of groups of anaerobic bacteria active in the rumen. J. Anim. Sci. 22, 801.

Bryant, M. P. \& Robinson, I. M. (1961). Some nutritional requirements of the genus Ruminococcus. Appl. Microbiol. 9, 91.

Bryant, M. P., Small, N., Bouma, C. \& Robinson, I. M. (1958). Characteristics of ruminal anaerobic cellulolytic cocei and Cillobacterium cellulosolvens, n.sp. J. Bart. 76, 529.

Bücher, T. \& Redetzki, H. (1951). Eine spezifische photometrische Bestimmung von Äthylalkohol auf fermentativem Wege. Klin. Wschr. 29, 615.

Cunningham, H. M. \& Brisson, G. J. (1955). Note on alcoholic fermentation in the stomachs of lambs fed high-glucose diets. Canad. J. agric. Sci. 35, 511.

Elsden, S. R. \& Gibson, Q. H. (1954). The estimation of lactic acid using ceric sulphate. Biochem. J. 58, 154.

Elsden, S. R. \& Phillipson, A. T. (1948). Ruminant digestion. Annu. Rev. Biochem. 17, 705.

EnfBo, L. (1949). On the formation of reducing sugars in thermophilic cellulose fermentation. Acta chem. scand. 3, 975.

Gilchrist, F. M. C. \& Kistner, A. (1962). Bacteria of the ovine rumen. I. The composition of the population on a diet of poor teff hay. J. agric. Sei. 59, 77 .

GILL, J. W. \& KING, K. W. (1958). Nutritional characteristics of a butyrivibrio. J. Bact. $75,666$.

Gray, F. V. \& Pilgrim, A. F. (1952). Origins of the volatile fatty acids in the rumen. Nature, Lond. 17!!, 375.

HaLl, E. R. (1952). Investigations on the microbiology of cellulose utilization in domestic rabbits. J. gen. Microbiol. 7, 350.

Heald, P. J. (1953). The fermentation of xylans in the rumen of the sheep. Brit. J. Nutr. $7,124$.

Hulcher, F. H. \& King, K. W. (1958). Disaccharide preference of an aerobic cellulolytic bacterium, Cellvibrio gilvus, n.sp. J. Bact. 76, 565.

Hobson, P. N. \& Purdom, M. R. (1961). 'Two types of xylan fermenting bacteria from the sheep rumen. J. appl. Bact. $24,188$.

Hungate, R. E. (1950). The anaerobic mesophilic cellulolytic bacteria. Bact. Rer. 14. 1 .

Hungate, R. E. (1957). Microorganisms in the rumen of cattle fed a constant ration. Canad. J. Microbiol. 3, 289.

Hungate, R. E. (1960). Symposium: Selected topics in microbial ecology. I. Microbial ecology of the rumen. Bact. Rev. 24, 353.

Hungate, R. E. (1963). Symbiotic associations: The rumen bacteria. In Symbiotic Associations, Symp. Soc. gen. Microbiol. 13, 266. 
James, A. T. \& Martin, A. J. P. (1952). Gas-liquid partition chromatography: the separation and micro-estimation of volatile fatty acids from formic acid to dodecanoic acid. Biochem. J. 50, 679 .

Kistner, A. (1960). An improved method for viable counts of bacteria of the ovine rumen which ferment carbohydrates. J. gen. Microbiol. 23, 565.

Kistner, A. \& Gouws, L. (1962). Effect of change of diet on the predominant type of cellulose-digesting bacteria in the rumen of sheep. Abstr. 8th int. Congr. Microbiol. p. 41.

Kistner, A., Gouws, L. \& Gilchrist, F. M. C. (1962). Bacteria of the ovine rumen. II. The functional groups fermenting carbohydrates and lactate on a diet of lucerne (Medicago sativa) hay. J. agric. Sci. 59, 85.

MCBEE, R. H. (1948). The culture and physiology of a thermophilic cellulose-fermenting bacterium. J. Bact. 56, 653 .

McNeill, J. J. \& Jacobson, D. R. (1955). Studies on the methane and hydrogen metabolism of bovine rumen bacteria. J. Dairy Sci. 38, 608.

Moomaw, C. R. \& Hungate, R. E. (1963). Ethanol conversion in the bovine rumen. J. Bact. 85, 721.

Neish, A. C. (1952). Analytical Methods for Bacterial Fermentations. Nat. Res. Coun. Canada, Rep. No. 46-8-3 (2nd revision), Saskatoon.

Peters, J. P. \& Van Slyke, D. D. (1932). Quantitative Clinical Chemistry. 2, Methods. Baltimore: The Williams and Wilkins Co.

SiJPesteiJn, A. K. (1951). On Ruminococcus flavefaciens, a cellulose-decomposing bacterium from the rumen of sheep and cattle. J. gen. Microbiol. 5, 869.

Skinner, F. A. (1960). The isolation of anaerobic cellulose-decomposing bacteria from soil. J. gen. Microbiol. 22, 539.

Smith, P. H. \& Hungate, R. E. (1958). Isolation and characterization of Methanobacterium ruminantium n.sp. J. Bact. 75, 713.

Woon, W. A. (1961). Fermentation of carbohydrates and related compounds. In The Bacteria, Vol. 2, Metabolism, p. 59. New York: Academic Press. 